\title{
A pesquisa em práticas sexuais: políticas e moralidades na academia
}

\section{The research on sexual practices: policies and moralities in the academy}

\section{Victor Hugo de Souza Barreto}

Doutor em Antropologia pela Universidade Federal Fluminense. Pesquisador de Pós-Doutorado do Programa de Pós-Graduação em Antropologia Social do Museu Nacional/UFRJ. Email: torugobarreto@yahoo.com.br

\section{Resumo:}

Neste trabalho apresento algumas aproximações e reflexões a partir da percepção de um cenário em que manifestações conservadoras e reacionárias tomam cada vez mais posição e disputa com relação a certos temas de pesquisa acadêmica. Parto aqui da apresentação de uma experiência pessoal, enquanto pesquisador de temas relativos a gênero e sexualidade, porém argumento que os temas de pesquisa que "incomodam" atravessam também diversos debates, principalmente aqueles que exponham certos "riscos sociais".

Palavras-chave: Sexualidade, Moralidades, Etnografia, Metodologia.

\section{Abstract:}

In this paper, I present some approximations and reflections based on the perception of a scenario in which conservative and reactionary reactions have been increasingly taking position and dispute with respect to certain themes of academic research. I begin with the presentation of a personal experience as a researcher on themes related to gender and sexuality, but I argue that the research themes that "bother" also cross several debates, especially those that expose certain "social risks".

Keywords: Sexuality, Moralities, Ethnography, Methodology. 


\section{INTRODUÇÃO}

O que torna uma pesquisa acadêmica incômoda? O que podemos pensar a partir dos recentes casos em que professores e pesquisadores tiveram seus trabalhos e objetos de pesquisa alvos de ataques virtuais e de perseguições de fundo moralista (em sua maioria), mas que cada vez mais transborda em violência efetiva? Quais são as implicações que tal cenário pode trazer não só para o debate no espaço público contemporâneo, mas também na maneira como nós desenvolvemos nossas pesquisas em suas diferentes etapas, desde a escolha do tema até sua divulgação? Essas são algumas das questões de que pretendo me aproximar nesse artigo. Digo "aproximar" porque meu objetivo não é apresentar respostas ou conclusões prontas e definitivas a elas, mas, sim, propor algumas reflexões. Contrariando também um desejo de nossa disciplina antropológica por um distanciamento relativizador em busca de uma objetividade ou neutralidade, parto aqui da apresentação de um caso pessoal para pensar as questões colocadas nesse início. Na verdade, foi justamente o fato de ter sido alvo desses ataques que me levou tanto a essas reflexões quanto a ser demandado para um certo posicionamento enquanto pesquisador de temáticas específicas.

Centralizo minhas observações no decorrer desse texto, portanto, a partir do tema das pesquisas em práticas sexuais não só porque é meu tema preferencial de pesquisas, mas também por perceber que é justamente no campo das questões de gênero e sexualidade em que esses ataques notavelmente se concentram. Porém o que apresento como argumento é que, apesar de alvo preferencial, esses temas não são os únicos que sofrem ataques. Meu ponto é que as pesquisas que costumam incomodar são justamente aquelas que explicitam determinados "riscos sociais", como espero deixar mais claro adiante.

Outra consideração importante é que tenho total consciência de que toda e qualquer pesquisa é passível de crítica, seja ela fruto de financiamento público ou privado. Contudo o que é percebido é que esses ataques não correspondem a críticas feitas aos argumentos e às análises daquilo apresentado nos trabalhos escolhidos como alvos, mas são colocados como a própria im- 
possibilidade de que pesquisas sobre determinados temas sejam feitas e sua relevância e que se estende a situações de ataques ao próprio pesquisador. A classificação de certas pesquisas como irrelevantes ou, mais ainda, como "menores", será retomada por mim nas conclusões desse texto, propondo uma torção nessa ideia de "menor" e abrindo espaço para uma potência minoritária.

Dessa forma, ainda que parta aqui de um caso e de uma trajetória pessoais, este texto não pretende ser um exercício narcisístico de defesa, justificativa ou lamentação. E independentemente de que seja impossível recorrer a uma neutralidade nesse caso, o esforço aqui é perceber que os comentários e ataques recebidos se inserem em uma lógica de entendimento e de disputa de poder maior que afeta não só a mim, como a outros pesquisadores (não apenas das questões de gênero e sexualidade), bem como ao espaço da universidade e da escola enquanto lugar de produção de conhecimento e de ensino crítico, quanto afeta também as disputas políticas em várias instâncias que significam o avanço ou o retrocesso por uma sociedade mais igualitária e respeitosa com os mais diversos movimentos minoritários.

\section{APRESENTAÇÃO DE UM CONTEXTO NACIONAL}

Em um recente artigo publicado em 2016, Adriana Vianna e Maria Elvira Díaz-Benítez buscam fazer um panorama atual das políticas envolvendo gênero e sexualidade no país, mais especificamente aquelas referentes a direitos LGBT e à questão do aborto. A metáfora usada pelas autoras é a de uma luta de boxe, de um ringue no qual diferentes discursos e perspectivas políticas disputam a legitimidade para exercício, visibilidade e conquista de direitos no Brasil. A escolha sobre o tema da sexualidade justifica-se: "Se todo sexo é político, como já afirmava Gayle Rubin décadas atrás, cada vez mais nos parece que é através das falas inflamadas sobre ou a partir dele que se alinham e antagonizam muitos dos protagonistas políticos do atual cenário" (VIANNA; DÍAZ-BENÍTEZ, 2016, p. 36). O embate no ringue realizado pelo amplo espectro de forças políticas no país, das mais conservadoras às mais progressis- 
tas, não só evoca a todo momento uma gramática referente a gênero, sexualidade ou "família" como forma de justificar ou exemplificar determinada maneira de conceber seu projeto político, como também implica ganhos e perdas efetivas em políticas públicas que pesam na balança do processo democrático ${ }^{1}$.

Acontece que nessa luta, como demonstram as autoras, estamos atualmente acuados "no canto do ringue". Se desde a virada dos anos 2000 conseguiu-se avanços significativos na disputa por direitos, sendo o mais famoso deles o reconhecimento em 2011 de uniões estáveis para casais do mesmo sexo, a segunda década do século XXI assistiu a golpes certeiros de grupos conservadores que vêm cada vez mais tomando volume e eco em diversos espaços públicos. Esses golpes podem ser exemplificados tanto pela PL que ficou conhecida como "cura gay" (a permissão de tratamentos para pessoas que queiram "deixar" de ser homossexuais²), como a suspensão do material educativo de prevenção à homofobia desenvolvido pelo Fundo Nacional de Desenvolvimento da Educação, apelidado pejorativamente de "kit gay" e acusado de "estimular promiscuidade e homossexualismo (sic)" nas crianças e nas famílias (VIANNA; DÍAZ-BENÍTEZ, 2016, p. 38).

Vemos aqui combinarem-se narrativas que tratam de pertencimentos religiosos, da natureza política e do papel do Estado, bem como de explicações sobre a própria sexualidade e sua mutabilidade. Longe, muito longe, de um combate unidimensional, o que percebemos no cenário contemporâneo é a mobilização de diferentes estratégias narrativas, de associação e de lobby político e também de embate moral estabelecidas em diálogo com a linguagem dos direitos humanos (ou com uma apropriação desta) para definir modos de gestão do gênero e da sexualidade (VIANNA; DÍAZ-BENÍTEZ, 2016, p. 38-39).

Um exemplo emblemático desse "embate" de regulações morais seria a retirada da menção aos termos "gênero", "orientação sexual" e "sexualidade"

\footnotetext{
O tema sobre a mútua constituição entre gênero e Estado e o rendimento teórico e metodológico na ideia de um "Estado generificado", ou seja, constituído por e através de relações, representações, gramáticas e afetos que acionam essa dimensão do gênero e da sexualidade em suas formas de gestão, de práticas e de representações, é revista por Vianna e Lowenkron (2017).

2 Para uma apresentação crítica sobre o desenvolvimento do debate sobre a "cura gay" ver textos de Fry e Carrara (2016) e de Macedo e Sívori (2018).
} 
do Plano Nacional de Educação em 2014 votada por vereadores, deputados e representantes da sociedade civil ligados a determinados segmentos religiosos e conservadores. Ou seja, da invisibilidade no espaço escolar das questões de gênero e sexualidade enquanto campo problematizador do social e da prevenção de práticas discriminatórias entre crianças e adolescentes. Essa decisão encontrou eco na mesma supressão de termos em diversos planos educacionais estaduais e municipais, além de medidas esdrúxulas como mandar arrancar páginas de livros didáticos que tratassem da questão antes que fossem distribuídos para alunos da rede pública. A justificativa para tais atos girou em torno da preocupação pela disseminação de uma certa "ideologia de gênero" (expressão que esses setores usam para acusar qualquer desnaturalização ou reconhecimento da diversidade de gênero e sexual) que estaria tomando conta dos espaços educacionais e representaria um perigo para crianças e adolescentes ${ }^{3}$.

Sergio Carrara aponta como essas decisões têm a ver com disputas inerentes à emergência de um novo regime ou dispositivo da sexualidade na cena contemporânea. Elas têm como fundo a produção desse novo "dispositivo" relacionado à emergência da noção de "direitos sexuais", ou seja, na possível passagem de um regime da sexualidade pautado na linguagem biomédica - tal como apontado por Foucault (2009) - para um novo regime pautado na linguagem sociojurídica, envolvendo os planos das moralidades, da racionalidade e da política. Esse novo regime não sucederia ou substituiria o antigo, pelo contrário, "convivem tensamente no cenário contemporâneo. Em distintos modos de articulação, de colisão ou de enfrentamento, desenham diferentes políticas sexuais e estilos de regulação moral" (CARRARA, 2015, p. 333).

Estariam em jogo nessa passagem, portanto, novos critérios para definir os limites do aceitável do ponto de vista da sexualidade - que passariam do caráter reprodutivo ou não das práticas sexuais para a consensualidade, o autocontrole e a responsabilidade - e novos estilos de regulação moral. Des-

\footnotetext{
Para um debate em torno da criação da categoria falaciosa de "ideologia de gênero" e sua correlação com uma suposta "doutrinação marxista" nas escolas apregoadas por diversas organizações e entidades que se agrupam em um movimento denominado "Escola Sem Partido", ver artigos de Miguel (2016) e de Viveros e Rondon (2017).
} 
se modo, "aumenta a inquietação (que às vezes assume a dimensão de pânico moral) em relação a fenômenos como a pedofilia, o assédio sexual, o abuso sexual, o turismo sexual, a exploração sexual, a compulsão sexual etc." (CARRARA, 2015, p. 332).

É importante perceber que esses pânicos morais desencadeados por tais inquietações referentes aos limites da sexualidade não são exclusivos dos espaços de decisões políticas e estatais; estes apenas são representantes maiores e produtores de uma cristalização ou desencadeamento de efeitos de regulação (com consequências mais significativas, obviamente). Porém outros territórios se tornam palco ou são estratégicos nesse sentido, como o das artes e o acadêmico, este último o território privilegiado para o desenvolvimento do meu argumento.

Se casos mais recentes como a presença de crianças em exposições ou performances artísticas que envolvam nudez; aquilo que pode ser exposto ou não nos museus a partir de um critério de ofensa à moralidade; a incitação ao boicote de empresas cujas propagandas comerciais veiculadas em diversas mídias adotem o discurso de valorização da tolerância e da diversidade sexual; a censura em algumas redes sociais de reproduções de quadros clássicos que apresentem situações eróticas ou de nudez; são exemplos que apontam para o avanço cada vez maior de uma onda conservadora e reacionária, também é possível perceber o quanto dessa regulação moral vem atingindo as produções acadêmicas e alcançando o próprio espaço universitário. Aqui, as acusações desdobram-se, somando argumentos de justificativas econômicas próprias de uma retórica que se construiu em torno de um contexto de crise política e econômica pós 2013. É o que pretendo apresentar adiante a partir de algumas repercussões e reações a meus trabalhos em particular.

\section{UM EXEMPLO PARTICULAR}

Durante os anos de 2010 a 2012 desenvolvi minha pesquisa para o mestrado em Antropologia sobre o tema da prostituição masculina. A etnogra- 
fia concentrou-se na observação e no acompanhamento da prática realizada em algumas saunas da cidade do Rio de Janeiro. A estratégia que adotei ali e que costumo retomar em meus trabalhos é a de tentar mapear esses campos através do elemento do desejo, tornando-o "objeto" e fio condutor da análise. O que proponho é me aproximar, portanto, de uma "antropologia do desejo" (PERLONGHER, 1993), procurando compreender de que forma são compostos ou acionados os fluxos de desejo que circulam na prática, como se agenciam e são atravessados por outros elementos, sejam eles monetários (como no caso do mercado da prostituição) ou não. Venho me dedicando, dessa forma, a cartografar e problematizar desejos que poderiam ser tidos, a princípio, como "dissidentes", e pesquisas que levem a sério o engajamento dos sujeitos em determinadas práticas sexuais. Daí também o fato de em minha pesquisa para o doutorado (2012-2016) ter desenvolvido uma tese sobre a prática do sexo grupal/coletivo realizada entre homens em reuniões ou eventos de orgia, mais especificamente uma etnografia de festas de orgia entre homens que acontecem na cidade do Rio de Janeiro. Note-se que esse primeiro recorte (o fato de ser um evento exclusivo para homens) não foi intencional. Foi uma característica dada pelo campo, que diz muito sobre como se constrói socialmente uma ideia de masculinidade, de invisibilidade do desejo sexual feminino e de relações entre os gêneros em nossa sociedade, e que foi um dos pontos que explorei naquele trabalho.

Algo que é importante já apontar é que a etnografia de práticas sexuais efetivas é um campo que vem se estabelecendo cada vez mais na antropologia brasileira. Os trabalhos com esses cenários etnográficos exploram como é possível produzir conhecimento das "práticas sexuais/eróticas que desafiam os efeitos políticos da repugnância e da transgressão". São trabalhos que lidam com os limites daquilo que se naturalizou achar aceitável, correto ou normal. "Abordam ainda as maneiras como se constroem subjetividades e identidades coletivas a partir de práticas sexuais alternativas, identificando suas condições de produção, suas transformações e os discursos que os agentes utilizam para legitimá-las" (FÍGAR; DÍAZ-BENITEZ, 2009, p. 21). Esses estudos acabam por permitir não só o entendimento dos limites das práticas em si, mas tam- 
bém das nossas próprias ferramentas de análise ao colocarem esses temas em questão. Para além de uma dicotomia entre norma e transgressão, meus interlocutores apontavam-me, da mesma forma, elaborações e construções próprias de gênero, principalmente de masculinidade, e no que isso se relaciona com as relações cotidianas de suas vidas em outros âmbitos para além daqueles cenários, seus entendimentos sobre a produção de uma sexualidade focada em uma busca de intensidade e de um desejo que é atravessado por questões mais diversas como reproduções normativas e de resistência relacionada a fatores como raça, classe, geração, violência, exposição a riscos e doenças e formas outras de prevenção ou de um cuidado de si.

Óbvio que ao trazer esses temas de pesquisa para o debate antropológico eu tinha ideia do tom provocativo que eles tinham. Ao colocar o sexo em debate, é difícil fugir de uma abordagem que não privilegie o tom do sensacionalismo, do curioso ou do bizarro. É muito fácil resvalar nesse tipo de aproximação com o tema, justamente pelo fato desse ser um dos pontos de percepção comumente encontrados em nossa sociedade. Funciona como nas chamadas de programas televisivos ou nas matérias que aparecem na internet que volta e meia abordam reportagens com temas relativos às práticas sexuais (swing, BDSM, sexo em público, fetichistas dos mais variados, prostituição etc.): "quem são? onde vivem? são pessoas normais? por que sentem prazer com isso?"; e nessas perguntas já se coloca e pré-determina toda uma série de exotizações e moralidades que pouco ajudam a compreender, de fato, o que essas pessoas fazem nos contextos abordados.

O riso, por exemplo, foi um dos elementos que me acompanharam (e ainda acompanham!) em todo o processo de produção desses trabalhos. Seja na academia ou fora dela o riso sempre aparecia. Em gargalhadas, em risos debochados, em risadas nervosas, "amarelas", em algo que poderia se entender como "sorrisos cúmplices" ou mesmo de uma hilaridade que parecia mais uma distensão de energia do que qualquer outra coisa. $O$ riso era algo com que tive de saber como lidar e também, de certa forma, aprender a usá-lo a meu favor. Se era aborrecido perceber sua recorrência e interrupção em reuniões de grupos de pesquisa, apresentação de seminários ou congressos, também per- 
cebi que poderia aproveitá-lo como forma de "sedução" do ouvinte ao que eu queria dizer. O desconforto causado pelas descrições etnográficas, distendidas e desarmadas com o riso (e caberia a mim saber os momentos estratégicos de utilizá-lo) dava abertura ao pensamento que eu propunha. Se o riso vinha como defesa do incômodo que causavam aquelas questões, haveria possibilidade de abertura para algo novo. Porém o riso espalhado pelo escárnio nas redes sociais tornou-se mais difícil de controlar. Demorou para que eu me desse conta, da mesma forma, de que o riso depreciativo que acompanhou os comentários subsequentes sobre as pesquisas era ele também um mecanismo de regulação a partir de certas moralidades.

Toda vez que comentava sobre minha pesquisa, portanto, durante esses anos, formal ou informalmente, dentro ou fora do ambiente acadêmico, mais do que dúvidas sobre minhas análises do campo, o que mais ouvia eram questionamentos (colocados das mais diferentes formas: irônicas, agressivas, surpresas, desconfiadas etc.) sobre acerca das minhas motivações, das condições em que seria/foi feito o trabalho de campo e da credibilidade das pesquisas. Talvez o primeiro clímax desses questionamentos tenha acontecido em março de 2015, quando uma comunidade na rede social do Facebook sobre trabalhos acadêmicos postou trechos de um artigo meu apresentado na Reunião da ANPOCS de 2014 a respeito de alguns resultados da pesquisa sobre as festas de orgia ${ }^{4}$. Seguiu-se uma série de posts com o link do meu currículo Lattes e também a postagem da minha dissertação ${ }^{5}$. Esses posts geraram uma discussão acalorada, com a maioria das reações sendo bem negativas e agressivas: "É para isso que o dinheiro público serve?? Que porcaria de banca é essa??"; "Vamo manerar na viadagem ae"; "Tanta enrolação só para dizer que adora dar o rabo?”; "Mais um rebento de Fucô"; fo-

\footnotetext{
Trata-se de artigo posteriormente publicado em Barreto (2018a). Detalho esse mesmo caso a partir da ideia de tabus em Barreto (2018b).

5 A página, que já conta com quase quatro mil seguidores, é um espaço no qual pessoas anônimas e/ou que se apresentam como pertencentes a variadas instituições de ensino superior, nacionais e internacionais, postam títulos, resumos, links de dissertações e teses, links de currículos lattes, imagens de defesas etc., de pesquisadores cujos temas elas consideram motivo de escárnio. Importante notar que os temas de dissertações e teses versam sobre gênero, sexualidade, religiões de matriz africana, cultura popular, uso de drogas, regionalismos, funk, devires, entre outros.
} 
ram alguns das centenas de comentários, além das mensagens privadas que recebi no meu perfil.

Porém um segundo grande momento de ataques aconteceu com a divulgação da publicação de ambas as pesquisas em livro que, coincidentemente, ocorreu na mesma época $(2017 \mathrm{a} ; 2017 \mathrm{~b})^{6}$. O tema, a natureza da pesquisa, os títulos provocativos (Vamos fazer uma sacanagem gostosa? e Festas de orgia para homens), o financiamento público da pesquisa (durante o mestrado tive uma bolsa pelo CNPq e durante o doutorado, uma bolsa "sanduíche" de nove meses para pesquisas no Centro em Rede de Investigação em Antropologia do ISCTE-IUL em Lisboa, também pelo CNPq) aliado à publicação por uma editora universitária fez que eu recebesse até ameaças de morte em mensagens públicas e privadas ("Cuidado, porque se eu te encontrar ao vivo é pra enfiar um cano de doze no seu cu e apertar o gatilho pra você saber o que é bom. Não é de enfiar coisa no cu que você gosta?", por exemplo).

Importante comentar também que paralelo ao desenvolvimento de maiores pesquisas sobre o tema e do recrudescimento dessa onda conservadora e moralista pelo país, esta última foi exarcebada pela retórica da "crise" econômica-política que veio crescendo exponencialmente desde o ano de 2013 no cenário nacional ${ }^{7}$. As pesquisas desenvolvidas nas universidades públicas sobre a temática de gênero e sexualidade costumam ser o alvo preferido de ataques

\footnotetext{
${ }^{6}$ A pesquisa do mestrado foi uma das selecionadas em edital anual interno da EdUFF, editora da Universidade Federal Fluminense, no qual trabalhos de diferentes áreas desenvolvidos pela universidade são escolhidos para publicação. Meu trabalho foi selecionado no edital de 2013, ainda que a publicação só tenha acontecido em 2017. A publicação da tese foi um convite da Editora Devires, especializada em trabalhos da área de gênero e sexualidade.

7 Tal contexto nacional vem sendo tema de diversas análises por diferentes ângulos e atores sociais. Inclusive como objeto preferencial de estudo em uma disciplina ministrada no Instituto de Ciência Política da UnB no primeiro semestre de 2018, intitulada "O golpe de 2016 e o futuro da democracia no Brasil". A notícia da oferta da disciplina em uma universidade pública causou grande polêmica com a ameaça de retaliação e suspensão das aulas e dos professores responsáveis. Diante de tais rumores, vários outros institutos de diferentes universidades pelo país propuseram o mesmo programa de disciplina como forma de apoio e resistência. Em sua ementa a disciplina elenca três objetivos principais: “(1) Entender os elementos de fragilidade do sistema político brasileiro que permitiram a ruptura democrática de maio e agosto de 2016, com a deposição da presidente Dilma Rousseff. (2) Analisar o governo presidido por Michel Temer e investigar o que sua agenda de retrocesso nos direitos e restrição às liberdades diz sobre a relação entre as desigualdades sociais e o sistema político no Brasil. (3) Perscrutar os desdobramentos da crise em curso e as possibilidades de reforço da resistência popular e de restabelecimento do Estado de direito e da democracia política no Brasil”.
} 
e críticas desse discurso reacionário, que passa tanto por ataques virtuais em redes sociais ou notícias de jornais quanto por agressões físicas e verbais pessoais em que professores, alunos e pesquisadores são intimidados e/ou agredidos em seus ambientes de trabalho, chegando até mesmo à invasão de salas em que defesas desses trabalhos são interrompidas ${ }^{8}$.

Tal cenário explica as reações raivosas à publicação em livro de minha dissertação e tese em 2017, que misturaram discursos de ódio e homofóbicos com uma retórica de uma suposta hierarquia de relevância e "utilidade" entre pesquisas e de contenção dos gastos públicos. Foram diversas chamadas de matérias reproduzidas impressas e virtualmente com títulos como: "Em universidade federal, doutorado sobre orgias gays tem 'participação especial' de autor", "Tese aprovada pela UFF traz termos chulos e imagens pornográficas", "Como ter um doutorado e verba fácil? Participe de orgia gay"; o que tanto alimentou comentários de ódio como: "O capeta precisa inventar logo algo pior que o HIV pra acabar com os sodomitas, fato!”, “Temos que EXTINGUIR as faculdades federais do Brasil. Todas. Sem exceção. Caso demore, pelo menos os cursos de humanas e sociais", "Ninguém pode negar que a bibinha suou e ralou um monte para merecer o dinheiro das bolsas pagas com o nosso dinheiro..." e "Que alegria ter nascido em 1974, época em que fumar era bonito e dar o cu era feio..."; quanto o argumento de mau uso do dinheiro público e que justamente por trabalhos como os meus que "o Brasil ainda não ganhou um prêmio Nobel" ou ainda não encontrou a "cura do câncer".

A violência recorrentemente acionada nos discursos de reação que recebi ao longo desses anos também mereceria um espaço de análise maior por si só. Chamo a atenção rapidamente não apenas para as mensagens de teor mais agressivo e direto como as ameaças de morte, mas para a brutalidade em sua maioria de teor homofóbico presente na maioria dos comentários que, inicialmente direcionados para a figura do pesquisador, rapidamente resvalam em grupos ou categorias maiores: pesquisadores de "humanas", "esquerdistas" ou "comunistas", universitários em geral e, principalmente, pessoas LGBT e suas práticas sexuais.

\footnotetext{
8 Ver a matéria disponível em: https://glo.bo/2R7T4EF.
} 
A hostilidade do discurso baseia-se no uso de termos ou ameaças violentas, mas que também se referem a práticas tidas como "nojentas" ou "repulsivas", do uso desses marcadores como uma forma política de processos de abjeção, repugnação e inferiorização de determinadas dinâmicas, de estabelecer uma certa hierarquia a partir de regulações morais. Nas diferentes formas de discriminação como o racismo, a misoginia, a homofobia e transfobia, encontramos uma dinâmica ativa desses mecanismos de desprezo e subjugo que fazem uso da humilhação, do nojo e do repúdio como aquilo que atualiza e reforça as distinções e marcações sociais ${ }^{9}$. Sexualidade e violência nessas falas constituem-se reciprocamente, ou seja, o acionamento de categorias que apelam tanto para um desprezo ou inferiorização quanto para uma brutalidade tem a ver com certas convenções de gênero e sexualidade e uma constitui a materialidade da outra ${ }^{10}$. O que quero dizer é que a agressividade dos comentários é indissociável de um certo entendimento da sexualidade e, principalmente, daquela que diz respeito a grupos minoritários ou ao que eu chamo em minhas pesquisas de "prazeres dissidentes".

No próximo item quero me deter um pouco mais sobre um dos pontos que me chamaram mais a atenção aos discursos e mensagens que recebi na esteira da divulgação de minhas pesquisas e que têm a ver com o desconforto do sexo no ambiente acadêmico: a certa fixação com minha suposta participação sexual durante o trabalho de campo.

\section{O PESQUISADOR COM “SEGUNDAS INTENÇÕES”}

Não tenho como fazer aqui um registro de todos os tipos e formas de comentários e dúvidas que ouvi relativos às minhas "motivações pessoais" para fazer essas pesquisas. Foram muitos, incessantes e variados, fossem

\footnotetext{
Devo essas conclusões às aulas e leituras do curso "Humilhação, nojo e repúdio no fazer social" ministrado pelos professores Maria Elvira Díaz-Benítez e Kaciano Gadelha, oferecido no primeiro semestre de 2017 no PPGAS do Museu Nacional/UFRJ.

${ }^{10} \mathrm{O}$ argumento de constituição recíproca entre gênero, sexualidade, crime e violência é apresentado de forma mais consistente por Efrem Filho (2017).
} 
num tom brincalhão, ou mesmo irônico, até chegar aos mais agressivos, em vários matizes de deboche e desconfiança. Ao que parece, não se pode escolher um tema desses de pesquisa sem que haja “algo por trás”, se não é um gosto pessoal relativo à minha sexualidade, uma desculpa para usufruir dos prazeres do campo ou mesmo uma maneira de teorizar e justificar uma "condição de homossexual"11. As notícias de jornais que falaram sobre o lançamento dos meus livros insistiam em chamar a atenção, por exemplo, para minha presença efetiva nos espaços durante as práticas sexuais e o descrédito de minhas análises, que se justificariam pela oportunidade de participação.

Se já é um consenso dentro das ciências humanas e sociais que a prática científica está longe de ser uma produção "distanciada”, “objetiva” ou "neutra", para aqueles que se dedicam a pesquisas relacionadas à sexualidade pesam, no entanto, uma contínua desconfiança e suspeita e, consequentemente, um descrédito "científico". A ideia da desconfiança, do pesquisador voyeur ou com motivações escusas é unanimemente apontada por aqueles que se dedicaram ao tema e também a alguns autores que fazem uma revisão geral do campo, seja no contexto norte-americano ou europeu (VANCE, 1995; IRVINE, 2003), apontando, inclusive, dificuldades práticas desses pesquisadores em conseguir bolsas, financiamentos, cargos quando formados, disputas em departamentos nas universidades etc.

Muitos fatores poderiam ser apontados para o fato da marginalização dos estudos sobre sexualidade (alguns inclusive já mencionados aqui), porém Irvine afirma que o principal seria a dominância de uma epistemologia positivista naquilo que se entende como ciência. A isso acrescenta-se a estigmatização do sujeito pesquisador posto sempre sob suspeita. Há uma espécie de “contaminação", nos termos colocados por Mary Douglas (1976), pelo tema

\footnotetext{
${ }^{11}$ Como em mensagem que recebi no meu perfil da rede social, na qual se faz uma referência à própria biografia de pensadores como Foucault, ou seja, o interesse do autor em pensar a criação de problemas como a homossexualidade como fenômenos histórico e social viria do fato do próprio autor ser um homossexual que estaria buscando respostas para a sua "condição". Isso se repetiria num chavão intelectual (também presente no campo das artes, aliás) de que os pesquisadores usariam desculpas para se estudar. Nesse caso, como mulheres estudam questões feministas; negros, as condições de desigualdade raciais; usuários de drogas, as substâncias psicoativas; e pessoas LGBT, os temas de sexualidade.
} 
daquele que o estuda ou se aproxima dele: "sexo é estigmatizado, assim como aqueles que o pesquisam":

Historicamente, aqueles que estudam sexo têm sido objeto de especulação pública sobre, sendo até atacados, a sua própria sexualidade. Este tem sido o caso, independentemente da identidade sexual do pesquisador, uma vez que como Goffman chama a atenção, aqueles que se associam a um indivíduo estigmatizado (ou assunto, neste caso), adquirem um "estigma cortesia" (IRVINE, 2003, p. 451).

No caso da Antropologia isso se aprofunda justamente pelo seu característico método etnográfico de trabalho, da necessidade de se estar em campo, "entre os nativos", de estar presente, de "observar-participar" aquilo que acontece. Uma coisa é você montar um questionário sobre os hábitos sexuais das pessoas e aplicá-lo, ou fazer entrevistas em que você pergunta para elas o que pensam e/ou costumam fazer na cama, no quarto e durante o sexo; outra coisa muito diferente é estar presente e ver de fato o que elas fazem. A ideia de uma pesquisa científica realizada nesses termos causa desconforto, descrença e desconfiança $\mathrm{a}^{12}$.

A década de 1980 é comumente representada como um ponto de virada na teoria antropológica. Foi um momento em que certos antropólogos começaram a fazer questionamentos reflexivos de alguns pressupostos que pareciam fundamentalmente arraigados ao arcabouço teórico e à prática de sua disciplina. Construída principalmente ao longo do século XX, a antropologia foi alvo, nesse momento, de autores que proclamavam a necessidade de uma renovação profunda do modo como ela era feita, de seus conceitos, seus princípios e objetivos, a partir de uma revisão crítica dos trabalhos produzidos até então. A antropologia neste momento também olhava para si mesma (MACEDO, 2011).

\footnotetext{
${ }^{12}$ É óbvio que cada campo de pesquisa etnográfica coloca diferentes questões de ordem ética e moral para o pesquisador, seja em relação com os próprios interlocutores durante o processo de pesquisa, seja no processo de produção de escrita e de compartilhamento do material de trabalho diante de uma "comunidade científica" e também fora do ambiente universitário. O já clássico trabalho de Vagner da Silva (2000) traz esses questionamentos relacionados a sua experiência no campo das religiões afro-brasileiras e que servem para pensar em diversos desafios que encontramos na posição de cientistas sociais.
} 
O paradigma da "reflexividade", que tem como expoente o trabalho de Rabinow acerca do trabalho de campo como uma operação colaborativa, na qual os interlocutores e o antropólogo constroem mutuamente explicações e interpretações (RABINOW, 1992), o interpretativismo e a inspiração hermenêutica (GEERTZ, 1989; 1997), bem como os questionamentos da chamada antropologia "pós-moderna" em sua vertente norte-americana (CLIFFORD; MARCUS, 1986; CLIFFORD, 1998), estabeleceram um campo de debates produtivo, que permitiu aos antropólogos, ao mesmo tempo, criticar a "autoridade etnográfica" calcada no mito da objetividade científica, problematizar a necessidade e as possibilidades da interlocução com os "nativos" e indagar acerca da necessidade da invisibilidade do pesquisador no texto antropológico (BRAZ; SILVEIRA, 2013).

Como já disse Braz (2010), parte da riqueza dos estudos sócio-antropológicos sobre sexualidades está presente justamente nos desafios epistemológicos e metodológicos que implicam para a reflexão e a prática antropológicas. Ao que parece, o estudo da sexualidade obriga o pesquisador a se ver ele próprio (e ser visto também) como ser sexuado, de desejo e produtor de desejo, uma subjetividade que é, de fato, colocada em jogo, como um agente que, de certa forma, precisa colocar-se também "sexualmente" em campo ${ }^{13}$.

Ao trazer algumas descrições do trabalho de campo, seja aquele realizado nas saunas de prostituição masculina ou nas festas de orgia, não narrei algum tipo de intercurso sexual do etnógrafo, se partirmos da ideia, digamos, convencional de sexo, isto é, penetrativa e genitalizada. Quando as pessoas me perguntam se "participei" dos eventos elas na verdade querem saber: "você penetrou ou foi penetrado por alguém?". Mas se considerarmos que a fronteira em torno de em que começa e termina o sexo é sempre contextual, "o sexo em

\footnotetext{
${ }_{13}$ Uma imagem interessante é aquela trazida por Díaz-Benítez em seu trabalho sobre a produção pornográfica mainstream no Brasil, em que a autora relata uma entrevista com um dos atores pornôs interlocutores realizada no intervalo de uma das filmagens, em que ele estava nu e se masturbando, já que precisava manter a ereção constante para o prosseguimento da cena (2010). A própria autora apresenta alguns comentários sobre os desafios etnográficos e o panorama latino-americano da produção sobre o tema (DÍAZ-BENÍTEZ, 2013). Também há uma pioneira coletânea de artigos organizada por Leap e Lewin (1996) em que diferentes antropólogos falam sobre sua experiência estudando diferentes culturas a partir de uma perspectiva gay ou lésbica, e o quanto a explicitação de uma orientação sexual pode determinar o acesso a contextos específicos, em que a sexualidade do pesquisador, de fato, importa.
} 
si deixa de ser apenas um ponto de partida analítico para uma interpretação antropológica e também se transforma em algo que deve, ao contrário, ser antropologicamente interpretado" (BRAZ; SILVEIRA, 2013).

Como afirmam Braz e Silveira (2013), o pesquisador pode não considerar que está fazendo sexo, já que sua observação tem outras intencionalidades que não passam, necessariamente, pelo voyeurismo. Mas da perspectiva dos sujeitos observados, ele pode estar. Os significados que eles atribuem ao sexo vão, muitas vezes, além de uma concepção penetrativa, genitalizada, e mesmo que envolva necessariamente só um toque, ou um simples olhar, como foi um dos casos narrados na introdução de minha tese, na qual dois rapazes pediram que eu apenas ficasse no ambiente enquanto eles faziam sexo, um desejo que passava apenas pela minha presença ali, que boa parte do prazer dos dois naquele momento passava por eu estar olhando aquela interação, era estar "fazendo sexo" com eles ${ }^{14}$.

A partir dessa etnografia percebo que para as pessoas interagindo nesse espaço, seja no dark room, (quarto escuro) ou nas suítes com camas coletivas, todos estão, ao menos para os sujeitos observados, "transando". Isto inclui, também, os antropólogos, que invariavelmente contribuem para que o desejo de fazer sexo em público ou em grupo de alguns sujeitos se realize ${ }^{15}$. Portanto, será que "em determinados contextos de trabalho de campo, a participação sexual do antropólogo é inerente ao 'estar lá?? Quais os limites da observação participante, quando nosso engajamento sexual é previsto, ainda que não tenhamos tal intenção?” (BRAZ; SILVEIRA, 2013). Talvez o risco aqui esteja em problematizar essas questões, mas ao mesmo tempo tendo o cuidado

\footnotetext{
${ }^{14}$ Ou então em uma situação mais "radical" que narro no livro sobre as festas de orgia (e que foi unanimemente citada pelas matérias e sites), de um "acidente" durante o trabalho de campo, quando, numa interação observada em um dos dark rooms numa festa em que se reuniam cerca de cinquenta homens num mesmo espaço, alguém subiu numa cama da qual eu estava próximo e ejaculou no meu rosto, atingindo esperma em minha boca e dentro do meu olho. Para os padrões da festa, o que essa pessoa fez está totalmente contra as "regras locais" de consentimento, uma gafe arbitrária e inconsequente que me obrigou a fazer um tratamento de seis meses com a profilaxia pós-exposição ao HIV, a PEP. Narrar esse fato me permitiu chamar a atenção para vários aspectos: as regras e normas locais, as situações de prazer/perigo experimentadas nesses espaços, o corpo como forma e instrumento de apreensão científica e certos desafios metodológicos que esse campo me trouxe.

${ }_{15}$ É ao artigo de Braz e Silveira (2013) a quem devo essa proposta de participação erótica inerente do pesquisador em determinados contextos de trabalho de campo.
} 
em não cair num discurso de mea culpa ou mesmo de um certo conservadorismo em nossas pesquisas.

O sociólogo norte-americano Laud Humpreys tem sido considerado o pioneiro neste tipo de estudo devido à Tearoom Trade, pesquisa que tratou dos encontros sexuais entre homens em banheiros públicos nos Estados Unidos, publicada em 1970. Ali o autor explica claramente que um dos métodos utilizados foi se colocar numa posição de voyeur das interações, já que essa figura, a do homem que participa das interações sexuais observando, era aceita naquele contexto. Era uma forma de "estar lá". A pesquisa de Humpreys recebeu severas críticas em seus aspectos éticos, e há como que um silenciamento acadêmico na problematização sobre "o sexo no trabalho de campo", tema que só retornaria à cena na década de 1990 .

A coletânea de textos organizada por Kulick e Willson (1995) abriu o caminho para a retomada dos debates em torno dessas questões. No Brasil podemos ver como esse trabalho estimulou a reflexão de outros pesquisadores (ROJO, 2003; BRAZ, 2010; dentre outros $\left.{ }^{16}\right)$. Esses trabalhos recentes fazem crítica à

proibição prescritiva do sexo em campo e ao silêncio disciplinar em torno dessa questão [...] acerca das implicações teórico-metodológicas e possibilidades interpretativas a partir de envolvimentos afetivo-sexuais do pesquisador em campo. Questionam mesmo a objetividade científica e colocam como impossível o completo distanciamento etnográfico (BRAZ, 2010, p. 40).

A própria mensagem que recebi de um dos interlocutores das festas de orgia chama a atenção para isso: "Conseguiu se libertar ou permaneceu como um legítimo voyerista?".

A questão é que a ideia de um estudo de campo sobre práticas sexuais gera, de fato, uma ansiedade. Minha posição aqui é que essa ansiedade não vem "do nada". Há motivos para ela acontecer que dizem muito mais sobre a forma

\footnotetext{
${ }^{16}$ Eu mesmo cheguei a fazer um pouco dessa discussão em outros espaços (BARRETO, 2017a, 2018b). Chamo a atenção também para a coletânea organizada por Bonetti e Fleischer (2007), na qual pesquisadoras mulheres destacam a especificidade do recorte de gênero em seus trabalhos de campo, problematizando situações de assédio e outros desafios pelos quais tiveram que passar.
} 
como vivemos nossa sexualidade e de certos posicionamentos e convenções morais em torno dela, do que da pesquisa em si. Há uma moralização do uso instrumental do sexo que aumenta a depender de quais práticas sexuais estamos falando ${ }^{17}$. O problema não é fazer sexo. O problema (moral) é alguém estudar sexo, é de qual o "tipo" de sexo que se fala e é de fazer sexo ali, da possibilidade disso ser colocado como método "científico". Ou, como conclui Irvine: "Uma certeza é que os estudos da sexualidade são intrinsicamente ligados à própria sexualidade; todas as ansiedades, prazeres, ambivalências e estigma que atribuímos ao sexo afetam a sua legitimidade como um subcampo da sociologia”. (IRVINE, 2003, p. 452)

O fato de que esse movimento de notícias depreciativas sobre certos trabalhos universitários que motivou esse artigo, ainda que concentre suas críticas nas pesquisas sobre gênero e sexualidade (pelos motivos já apontados anteriormente), também tenha como alvo temas outros é indicativo de uma problemática maior que gostaria de chamar a atenção a seguir. Meu argumento é que o problema se coloca a partir de trabalhos que lidem com nossas barreiras sociais em diversos âmbitos. A onda conservadora e moralista é "contra" qualquer pesquisa que ouse explicitar ou que leve a sério justamente alguns dos nossos "riscos sociais".

\section{AS PESQUISAS QUE INCOMODAM}

Em junho de 2017 um jornal de grande circulação, principalmente virtual, da cidade de Curitiba, publicou matéria com a seguinte chamada: "Dez monografias incomuns bancadas com dinheiro público". No texto eram listadas dissertações de mestrado e teses de doutorado (em sua maioria pertencentes às chamadas "ciências humanas") sobre temas tidos pela publicação como "pouco usuais", "pouco convencionais" ou "pouco ortodoxos". Os temas? Dos

\footnotetext{
7 A ideia de uma hierarquia sobre as práticas sexuais se deslocando de um eixo do mais "aceitável" como o sexo heterossexual monogâmica e reprodutivo até tudo aquilo que se diferenciasse ou escapasse disso propulsando certos "pânicos morais" é tributária de um texto clássico de Rubin (1998). Ver também artigo de Weeks sobre as políticas morais em torno da diversidade sexual (1985).
} 
dez trabalhos listados, seis tratavam de questões relativas a gênero e sexualidade, desde práticas homoeróticas em espaços públicos, passando pelo contemporâneo uso de aplicativos de celular para encontros, até análises sobre feminismos e diferentes representações da figura da mulher; os outros quatro dedicavam-se ao aparecimento e crescimento de fenômenos culturais contemporâneos como o mangá, os youtubers e estéticas e estilos musicais como o sertanejo universitário e o funk.

Dentro dessa lista dois dos trabalhos acabaram chamando mais a atenção. A dissertação de mestrado em Antropologia de Tedson Souza (2012) sobre a prática do "banheirão" em alguns lugares da cidade de Salvador pela UFBA. O autor ali buscou analisar os encontros homoeróticos, em sua maioria rápidos e anônimos, realizados em banheiros públicos masculinos, a partir de determinados marcadores sociais da diferença como classe, raça, gênero, idade etc. A inspiração na já citada pesquisa de Humphreys é óbvia, contudo o que acabou por chamar a atenção pela "crítica" das notícias foi justamente a escolha metodológica do pesquisador por uma "autoetnografia" em que ele relatava ter interagido sexualmente com seus interlocutores durante o trabalho de campo.

O segundo trabalho mais comentado da lista foi a tese de doutorado em antropologia pelo IFCS/UFRJ de Mylene Mizrahi, publicada em livro (2017), em que a autora efetua uma análise sobre a criação de uma estética própria dentro do estilo musical carioca funk. Sua etnografia focaliza a figura do cantor Mr. Catra, figura polêmica e contraditória por suas letras de forte teor sexual, uso de drogas e de um discurso próximo ao que se chama de "proibidão", tipo de letra que retrata a realidade violenta de comunidades em que a crítica a forças de repressão como a polícia é contínuas. A etnografia de Mylene, portanto, é toda voltada para a potência de criação e conectividade de pessoas em sua maioria negras, moradoras de comunidade e que elaboram um estilo de vida e de consumo próprio a partir de um ritmo musical marginalizado.

A matéria do jornal causou grande repercussão, sendo reproduzida e compartilhada em várias plataformas digitais, acompanhada do po- 
sicionamento não só de professores e pesquisadores, mas também de jornalistas, figuras políticas e mesmo de um promotor do Ministério Público do Distrito Federal. Ainda que o próprio jornal tenha aberto espaço para uma resposta da pesquisadora autora da tese sobre Mr. Catra, que alertava para a reprodução e os perigos de um pensamento elitista e preconceituoso contidos naquela matéria, essa resposta foi acompanhada de outro texto do próprio jornal de tom "conclusivo" sobre o debate que reafirmava a ideia de que "pesquisas alternativas" ou "pouco relevantes" não deveriam ser financiadas, já que em um contexto de crise atual como o do país "os recursos são finitos" e "a universidade deve buscar a elevação, e não o rebaixamento moral".

A patrulha pelas pesquisas responsáveis por um "rebaixamento moral" já tinha vindo também com as reações agressivas à dissertação de mestrado em Cultura e Territorialidades pela UFF de Mariana Caetano sobre a representação feminina também em letras do funk (2015). O eixo de análise da pesquisadora foi a figura e a obra da cantora Valesca Popozuda, através da qual Mariana discute a tensão entre hipersexualização e resistência com agência feminina, numa relação entre o funk e os discursos feministas.

O trabalho de Mariana, mesmo antes de sua finalização, foi um das centenas que foram alvos da comunidade do Facebook sobre trabalhos acadêmicos da qual falei anteriormente, junto com o de outros temas. Como a tese de doutorado em antropologia, também pela UFF, de Marcos Veríssimo, sobre as diferentes formas de consumo e cultivo caseiro de maconha no Rio de Janeiro e em Buenos Aires (2013). Não foram poucos os comentários agressivos que o autor recebeu e mesmo a ameaça com processos por um suposto incentivo ao uso de drogas ou de estímulo ao tráfico de substâncias criminosas. A lista de trabalhos atacados poderia continuar, porém meu ponto com esses exemplos é apontar como o incômodo de fundo moral vem justamente com pesquisas que ousem lidar com o que estou chamando aqui de "riscos sociais".

Utilizo a ideia de "risco social" inspirado no trabalho de Anne McClintock (2010) a partir de sua análise sobre a construção do projeto co- 
lonialista e imperialista britânico, que a autora demonstra como atravessado por relações constituintes entre raça e sexualidade, fetichismo e dinheiro, gênero e violência, domesticidade e mercado. Os "riscos sociais" para a autora seriam uma espécie de tensor, explicitado em situações de conflito ou teatralizado continuamente nas mais diferentes situações sociais nas quais formas de organização e (re)presentação de hierarquias e relações de poder, através dos chamados marcadores sociais da diferença, poderiam ser (re)conhecidas seja por sua afirmação normativa, seja por possibilidades de resistência ou torções.

Os trabalhos elencados aqui e que costumam ser alvos das críticas que aponto nessa pesquisa procuram exatamente explicitar certos "riscos sociais" e relativizar algumas concepções naturalizadas, arraigadas e moralistas de nossas vidas e de modos de existência outros. Tanto que os temas criticados e debochados na comunidade citada e nas matérias são aqueles que procuram pôr em cheque nossas concepções de desejo, de gênero e sexualidade, de família ou religião, e mesmo de cultura ou de uma desejada "elevação moral"; apontam nossos preconceitos e mostram como somos uma sociedade que ainda prega valores que nos desigualam em vários aspectos, seja socialmente, economicamente, racialmente etc.

A questão é que ver expostos esses temas e assuntos (e num espaço de status como o campo intelectual e acadêmico) não parece certo, chega a ser pornográfico, é obsceno, é colocar na luz algo que não deveria estar ali, incomoda. Incomoda e é um problema. O problema dessas pesquisas é que elas fazem justamente (re)pensar esses preceitos, valores e normas.

\section{AS POSSIBILIDADES VIRTUAIS E POR UMA PESQUISA "MENOR"}

Gostaria de nessas linhas finais comentar rapidamente sobre a atual importância e destaque que o espaço das redes sociais e da Internet alcançaram enquanto locus privilegiado tanto de protagonismo no "novo espaço público 
brasileiro" (BOSCO, 2017), quanto de meio que explicita e desenvolve os debates em torno das políticas e das moralidades que entendo compor o cenário nacional contemporâneo ${ }^{18}$. Não é à toa que conceitos como "empoderamento", "lugar de fala" e "representatividade" presentes na agenda dos atuais debates identitários encontrem nas redes sociais um espaço de luta e que desafia cada vez mais a produção de nosso conhecimento antropológico (MEDEIROS, 2018).

O campo de possibilidades e de usos das redes virtuais é inimaginável. Espaço liso e de fuga por excelência, a Internet já demonstrou ser um lugar alternativo aos mais variados aparelhos de captura de nossa sociedade de controle, desde a grande mídia até os governos mais conservadores, seja no Brasil ou em qualquer outra parte. A potência desses espaços como luta e resistência vem se demonstrando cada vez mais no fenômeno ativista, de formações de multidões, mudando a forma de se fazer política no mundo e como ferramenta indispensável nos novos movimentos sociais (MALINI; ANTOUN, 2013).

Porém, da mesma forma e com a mesma potência, a Internet parece ser um espaço ideal no qual os nossos microfascismos podem tomar forma, ser verbalizados e encontrar ressonância com os dos outros, pelo próprio efeito de "bolha" que certos usos das redes permitem. Também é uma forma de fazer política e de estratégia micropolítica, visando interferir nas possibilidades de engajamentos, por mais simples que sejam ${ }^{19}$.

A atitude de perseguição com as pesquisas apontadas anteriormente, as reações junto com os comentários e as mensagens agressivas recebidas podem estar nos limites de um fenômeno que atualmente se convencionou chamar de cyberbullying, que é esse tipo de assédio, hostilidade e agressão através do uso das novas tecnologias de informação e comunicação. Um tipo de assédio de maiores proporções pelo próprio alcance que essas informações e posta-

\footnotetext{
${ }_{18}$ A ideia de "um novo espaço público brasileiro" de Francisco Bosco é elaborada a partir do reconhecimento de um novo cenário a partir da segunda década do século XXI caracterizado principalmente por um acirramento de lutas identitárias. O autor destaca três fatores para que essas lutas se expandissem e se aprofundassem: as revoltas de junho de 2013, o colapso do lulismo e a enorme adesão ao uso de redes sociais digitais (2017, p. 54).

19 Agradeço à colega Flavia Medeiros por chamar minha atenção para este último ponto.
} 
gens podem ter por meio da rede ${ }^{20}$, contudo são reflexo também dessa disputa por novas formas de regulação política e moral no cenário nacional que chamei atenção no início do texto a partir das análises de Carrara (2015) e Díaz-Benítez e Vianna (2016).

O incômodo provocado pelas pesquisas elencadas aqui, como espero ter deixado claro, vem do fato justamente de serem trabalhos que não atendem a um interesse majoritário, seja de ordem estatal ou de qualquer lógica moralista que corresponda a ela, mas de serem assuntos tidos como "menores" ou "minoritários". Minha proposta é de torção dessa acusação ou depreciação como algo menor. Utilizo aqui as ideias que Deleuze e Guattari trazem sobre a potência do "menor". Para esses autores, menor e maior não se definem por uma questão numérica, de quantidade. A menoridade, nesse pensamento, se dá em termos qualitativos, na sua apresentação como diferença e pluralidade frente ao que se estabelece como padrão e norma:

A noção de minoria, com suas remissões musicais, literárias, linguísticas, mas também jurídicas, políticas, é bastante complexa. Minoria e maioria não se opõem apenas de uma maneira quantitativa. Maioria implica uma constante, de expressão ou de conteúdo, como um metro padrão em relação ao qual ela é avaliada. Suponhamos que a constante ou metro seja homem-branco-masculino-adulto-habitante das cidades-falante de uma língua padrão-europeu-heterossexual qualquer. É evidente que "o homem" tem a maioria, mesmo se é menos numeroso que os mosquitos, as crianças, as mulheres, os negros, os camponeses, os homossexuais... etc. A maioria supõe um estado de poder e de dominação, e não o contrário. Supõe o metro padrão e não o contrário (DELEUZE; GUATTARI, 1995, p. 55).

Trata-se da importância política, portanto, de um “devir-menor" ou "devir-minoritário" que se apresente como contrassenso e contradiscurso majoritário. A reflexão aqui é necessária para que se impeça que os espaços de produção e conhecimentos (como os acadêmicos e artísticos) tornem-se mera re-

\footnotetext{
${ }^{20}$ Outro fenômeno relacionado das redes sociais seriam as fake news, notícias e boatos falsos que rapidamente se espalham por efeito das repostagens e do compartilhamento sem checagem de fontes. Não é de se estranhar que as fake news venham sendo usadas como recurso político e de contribuição para a disseminação de pânicos morais.
} 
produção articulada de uma forma dominante de pensamento ou de uma lógica voltada a qualquer ideia ou projeto (de nação?) positivista, moralista e mercadológica conservadora de "progresso" ou "desenvolvimentismo". Mas que, em outro sentido, estimulem singularidades "menores" e "minoritárias". Por uma política acadêmica incômoda do "menor".

\section{REFERÊNCIAS}

1. BARRETO, Victor Hugo de Souza. Vamos fazer uma sacanagem gostosa? Uma etnografia da prostituição masculina carioca. Niterói: EdUFF, 2017a.

2. BARRETO, Victor Hugo de Souza. Festas de orgia para homens: territórios de intensidade e socialidade masculina. Salvador: Editora Devires, 2017b.

3. BARRETO, Victor Hugo de Souza. O "princípio da putaria" nas orgias masculinas: diferença e singularidade no corpo orgiástico. In: FERNANDES, Camila; RANGEL, Everton; LIMA, Fátima (Org.) (Des)Prazer da norma. Rio de Janeiro: Papéis Selvagens, 2018a.

4. BARRETO, Victor Hugo de Souza. Quando a pesquisa é o problema: o tabu no estudo das práticas sexuais. Cadernos de Campo, USP, v. 1, n. 26, p. 271-294, 2018 b.

5. BONETTI, Alinne; FLEISCHER, Soraya. Entre saias justas e jogos de cintura. Florianópolis: Ed. Mulheres; Santa Cruz do Sul: EDUNISC, 2007.

6. BOSCO, Francisco. A vítima tem sempre razão? São Paulo: Todavia, 2017.

7. BRAZ, Camilo Albuquerque de. À meia-luz: uma etnografia imprópria em clubes de sexo masculinos. Tese (Doutorado em Ciências Sociais), Universidade Estadual de Campinas, Campinas, SP, 2010.

8. BRAZ, Camilo Albuquerque de; SILVEIRA, Raphael. Nos limites da cena: reflexões metodológicas sobre o "estar lá" em contextos eróticos. Trabalho apresentado na X Reunión de Antropologia del Mercosur, Cordoba, Argentina, 2013.

9. CAETANO, Mariana Gomes. My Pussy é o Poder. Representação feminina através do funk: identidade, feminismo e indústria cultural. Dissertação (Mestrado em Cultura e Territorialidades), PPGCT, Universidade Federal Fluminense, Rio de Janeiro, 2015.

10. CARRARA, Sérgio. Moralidades, racionalidades e políticas sexuais no Brasil contemporâneo. Mana, Rio de Janeiro, v. 21, n. 2, p. 323-345, 2015. 
11. CLIFFORD, James. A experiência etnográfica: antropologia e literatura no século XX. Rio de Janeiro: Editora UFRJ, 1998.

12. CLIFFORD, James; MARCUS, George. Writing Culture. The poetics and politics of ethnography. Los Angeles: University of California Press, 1986.

13. DELEUZE, Gilles; GUATTARI, Félix. Mil platôs. Volume 2. São Paulo: Ed. 34, 1995.

14. DÍAZ-BENITEZ, María Elvira. Nas redes do sexo: os bastidores do pornô brasileiro. Rio de Janeiro: Zahar, 2010.

15. DÍAZ-BENITEZ, María Elvira. Algunos comentarios sobre practicas sexuales y sus desafios etnograficos. Apuntes de Investigación del CECYP, v. XVI, p. 13-33, 2013.

16. DOUGLAS, Mary. Pureza e Perigo. São Paulo: Editora Perspectiva, 1976.

17. EFREM FILHO, Roberto. Mata-Mata: reciprocidades constitutivas entre classe, gênero, sexualidade e território. Tese (Doutorado em Ciências Sociais), Universidade Estadual de Campinas, Campinas, SP, 2017.

18. FIGARI, Carlos; DÍAZ-BENÍTEZ, Maria Elvira. Introdução. Sexualidades que importam: entre a perversão e a dissidência. In: DÍAZ-BENÍTEZ, María Elvira; FÍGARI, Carlos (Org.). Prazeres dissidentes. Rio de Janeiro: Editora Garamond, 2009.

19. FOUCAULT, Michel. História da sexualidade 1: a vontade de saber. Rio de Janeiro: Graal, 2009.

20. FRY, Peter; CARRARA, Sergio. “Se oriente, rapaz!”: onde ficam os antropólogos em relação a pastores, geneticistas e tantos "outros" nas controvérsias sobre as "causas" da homossexualidade? Revista de Antropologia, São Paulo, v. 59, n. 01, p. 258-280, 2016.

21. GEERTZ, Clifford. A interpretação das culturas. Rio de Janeiro: LTC, 1989.

22. GEERTZ, Clifford. O saber local: novos ensaios em antropologia interpretativa. Petrópolis: Vozes, 1997.

23. HUMPHREYS, Laud. Tearoom trade: impersonal sex on public places. Chicago: Aldine, 1970.

24. IRVINE, Janice. The Sociologist as Voyeur: Social Theory and Sexuality Research, 1910- 1978. Qualitative Sociology, v. 26, n. 4, p. 429-456, 2003.

25. KULICK, Don; WILLSON, Margaret. Taboo: Sex, identity, and erotic subjectivity in anthropological fieldwork. London and New York: Routledge, 1995.

26. LEAP, William; LEWIN, Ellen (Org.) Out in the Field: Reflections of Lesbian and Gay Anthropologists. University of Illinois Press, 1996. 
27. MACEDO, Eric Silva. Outros outros: etnocentrismo e perspectiva. Dissertação (Mestrado em Antropologia), Universidade Federal Fluminense, Rio de Janeiro, 2011.

28. MACEDO, Cleber; SIVORI, Horacio. A “cura gay" e o campo evangélico no Brasil: panorama de uma década. In: OLIVEIRA, Leandro de; NATIVIDADE, Marcelo (Org.). A reinvenção da família: pertencimentos, fronteiras e transformações. Rio de Janeiro, Mar de Ideias, 2018 (no prelo).

29. MALINI, Fabio; ANTOUN, Henrique. A internet e a rua: ciberativismo e mobilização nas redes sociais. Porto Alegre: Sulina, 2013.

30. MCCLINTOCK, Anne. Couro imperial: raça, gênero e sexualidade no embate colonial. Campinas: Editora da UNICAMP, 2010.

31. MEDEIROS, Flavia. Adversidades e lugares de fala na produção do conhecimento etnográfico com policiais civis. Cadernos de Campo, USP, 2018 (no prelo).

32. MIGUEL, Luís Felipe. Da "doutrinação marxista” à “ideologia de gênero". Escola Sem Partido e as leis da mordaça no parlamento brasileiro. Direito \& Práxis, Rio de Janeiro, v. 7, n. 15, 2016.

33. MIZRAHI, Mylene. A estética funk carioca: criação e conectividade em Mr. Catra. Rio de Janeiro: 7 Letras, 2014.

34. PERLONGHER, Nestor. Antropologia das sociedades complexas, identidade e territorialidade ou como estava vestida Margaret Mead. Revista Brasileira de Ciências Sociais, v. 22, p. 137-144, 1993.

35. RABINOW, Paul. Reflexiones sobre un trabajo de campo en Marruecos. Madrid: Ediciones Júcar, 1992.

36. ROJO, Luiz Fernando. Rompendo tabus: a subjetividade erótica no trabalho de campo. Comunicação apresentada na V Reunião de Antropologia do Mercosul, Florianópolis, RAM, 2003.

37. RUBIN, Gayle. Thinking Sex: notes for a radical theory of the politics of sexuality. In: NARDI, Peter M.; SCHNEIDER, Berth E. (Ed.). Social perspectives in lesbian and gay studies: a reader. New York: Routledge, 1998

38. SOUZA, Tedson da Silva. Fazer banheirão: as dinâmicas das interações homoeróticas nos sanitários públicos da Estação da Lapa e adjacências. Dissertação (Mestrado em Antropologia), PPGA, Universidade Federal da Bahia, 2012.

39. DA SILVA, Vagner Gonçalves. O antropólogo e sua magia: trabalho de campo e texto etnográfico nas pesquisas antropológicas sobre as religiões afro-brasileiras. São Paulo, Edusp, 2000. 
40. VANCE, Carole. A antropologia redescobre a sexualidade: um comentário teórico. Physis: Revista de Saúde Coletiva, v. 5, n. 1, p. 7-31. IMS/UERJ: Relume-Dumará, 1995.

41. VERÍSSIMO, Marcos Alexandre. Maconheiros, fumons e growers: um estudo comparativo dos usos e cultivo caseiro de canábis no Rio de Janeiro e em Buenos Aires. Tese (Doutorado em Antropologia), PPGA, Universidade Federal Fluminense, Rio de Janeiro, 2013.

42. VIANNA, Adriana; DÍAZ-BENÍTEZ, Maria Elvira. Gênero e sexualidade: estamos no canto do ringue?. Cadernos de Campo, USP, v. 25, p. 36, 2016.

43. VIANNA, Adriana; LOWENKRON, Laura. O duplo fazer do gênero e do Estado: interconexões, materialidades e linguagens. Cadernos Pagu, n. 51, 2017.

44. VIVEROS, Mara; RONDON, Manuel Alejandro Rodríguez. Hacer y deshacer la ideología de género. Sexualidad, Salud y Sociedad, Rio de Janeiro, n. 27, p. 118127, dez. 2017.

45. WEEKS. Jefrey. The meaning of diversity. Sexuality and its discontents: meanings, myths and modern sexualities. Londres, Routledge, 1985. 